\title{
Escola de Games em tempos de pandemia: como promover a equidade de acesso aos participantes?
}

\author{
Tamara Cristina Ferreira \\ Universidade Federal de Jataí \\ Jataí, Goiás, Brasil \\ tamara.cristina@discente.ufg.br \\ Hugo Francisco M. Barreto \\ Universidade Federal de Jataí \\ Jataí, Goiás, Brasil \\ hugomedeiros@discente.ufg.br
}

\author{
Luciano Ferreira de C. Neto \\ Universidade Federal de Jataí \\ Jataí, Goiás, Brasil \\ lucianoneto@discente.ufg.br \\ Ligia Gouveia Silva \\ Universidade Federal de Jataí \\ Jataí, Goiás, Brasil \\ ligiagouveia@discente.ufg.br
}

\author{
Pedro Henrique M. Franco \\ Universidade Federal de Jataí \\ Jataí, Goiás, Brasil \\ pedrofranco@discente.ufg.br \\ Ana Paula F. V. Boaventura \\ Universidade Federal de Jataí \\ Jataí, Goiás, Brasil \\ ana_vilela@ufg.br
}

Segundo Barcelos e Silveira [1], a falta do domínio de conhecimentos matemáticos pelos alunos da área de Tecnologia é um possível fator explicativo para a falta de interesse e evasão em cursos da área. Os autores também apontam que o Pensamento Computacional (PC) vem como uma proposta de auxílio à obtenção de habilidades em Matemática por estar diretamente ligado à habilidade de resolver ou interpretar problemas, sendo a utilização de programação de computadores uma das práticas mais utilizadas para desenvolver tais habilidades.

Além disso, grandes organizações têm reconhecido a importância de ensinar programação na educação básica. "O desenvolvimento de algoritmos é o eixo central para todas as áreas relacionadas com a Computação, todavia, não deveria ser objeto de interesse apenas de estudantes de Computação" [2].

Neste contexto, o projeto de extensão "Escola de Games" tem por objetivo promover e desenvolver a equidade técnica e integração social de crianças e jovens estudantes da rede pública de ensino, do município de Jataí-Goiás. Por conseguinte, busca despertar o interesse profissional para o curso Ciências da Computação, ensinando programação por meio da linguagem de blocos Scratch.

Constata-se que há uma inovação ao convergir duas dimensões centrais do PC (abstração e algoritmo). Afinal, a abstração é desenvolvida por meio do Roteiro de Jogos e a dimensão do algoritmo é vislumbrada pela construção do jogo. Este propósito está alinhado à abstração de problemas, que é uma questão central do PC [4], que por sua vez é recomendado pela Base Nacional Comum Curricular e pela Sociedade Brasileira em Computação.

Desde o seu início, em 2017, o projeto é desenvolvido em ciclos anuais que visam: (1) Identificar unidades escolares e definir turmas a serem atendidas; (2) Produção de materiais; (3) Capacitação de novos membros (universitários monitores); (4) Aplicação para as turmas selecionadas; (5) Resultados; (6) Publicização e produção científica.

Fica permitido ao(s) autor(es) ou a terceiros a reprodução ou distribuição, em parte ou no todo, do material extraído dessa obra, de forma verbatim, adaptada ou remixada, bem como a criação ou produção a partir do conteúdo dessa obra, para fins não comerciais, desde que sejam atribuídos os devidos créditos à criação original, sob os termos da licença CC BY-NC 4.0.

EduComp'21, Abril 26-30, 2021, Jataí, Goiás, Brasil (On-line)

(c) 2021 Copyright mantido pelo(s) autor(es). Direitos de publicação licenciados à Sociedade Brasileira de Computação (SBC).
Destacam-se como pontos relevantes: 1) Ludicidade em abordar conceitos abstratos com a construção dos games; 2) Capacitação para integração de novos membros, afinal há um processo cíclico de trocas de aprendizagem entre os participantes; produções científicas; 3) Premiações de trabalhos em Congressos; 4) Feedbacks positivos da comunidade em geral, no que tange à organização e aplicação dos conteúdos.

Devido à COVID-19, o ano de 2020 trouxe novos desafios para a condução do projeto. No estado de Goiás, todos os estabelecimentos de ensino passaram a operar no formato de ensino remoto. Precisouse readequar o formato para dar continuidade ao projeto.

Em linhas gerais, para a aplicação do cuso houve um chamado por meio de redes sociais. O curso foi ministrado via Google Meet e os conteúdos foram aplicados remotamente. Os materiais foram compartilhados via Google Drive. As dúvidas eram sanadas através do grupo de WhatsApp, criado pelos monitores do projeto. No total se inscreveram 20 alunos, na faixa etária de 13 e 15 anos. Por motivos de falta de equipamentos/acesso à internet quatro não puderam participar das capacitações e, por fim, nove (9) concluíram o curso.

A etapa de aplicação foi feita por cinco monitores que se revezaram em 10 encontros, ficando cada um responsável pela condução de dois encontros. A participação dos professores universitários se deu na orientação aos monitores. Já a participação dos professores das unidades escolares foi inexistente, pois não houve a relação direta entre a aplicação do curso numa determinada escola.

De acordo com [3], o acesso às ferramentas digitais e Internet de qualidade são fundamentais nesse processo, sendo assim, algumas dificuldades foram observadas em relação à aplicação do minicurso na modalidade remota pelo Escola de Games. Para exemplificar, foi necessário estabelecer o pré-requisito aos interessados (jovem participante) em possuir computador e acesso à Internet e também não foi possível limitar o público alvo a uma única instituição. Por consequência, não houve uma padronização dos conteúdos dos roteiros com vistas a reforçar os conceitos aprendidos em sala de aula. Assim sendo, devido à pandemia não foi possível promover a equidade de oportunidade de acesso à inclusão tecnológica. Afinal, uma parcela dos interessados não tiveram condições materiais para a realização do minicurso de forma remota.

\section{REFERÊNCIAS}

[1] Thiago Schumacher Barcelos and Ismar Frango Silveira. 2012. Pensamento computacional e educação matemática: Relações para o ensino de computação na 
educação básica. In XX Workshop sobre Educação em Computação, Curitiba. Anais do XXXII CSBC, Vol. 2. 23

[2] Pasqueline Dantas Scaico, Anderson Alves de Lima, Silvia Azevedo, Jefferson Barbosa Belo da Silva, Ewerton Henning Raposo, Yugo Alencar, João Paulo Mendes, Alexandre Scaico, et al. 2013. Ensino de programação no ensino médio: Uma abordagem orientada ao design com a linguagem scratch. Revista Brasileira de
Informática na Educação 21, 02 (2013), 92.

[3] Julyanna Januário do Nascimento Souza. 2020. O processo avaliativo da matemática durante o período de ensino remoto emergencial. (2020).

[4] Jeannette M Wing. 2006. Computational thinking. Commun. ACM 49, 3 (2006), 33-35. 